\title{
Identification and Characterization of an OSH1 Thiol Reductase from Populus trichocarpa
}

\author{
Hui Wei ${ }^{1,+}$, Jie Zhou ${ }^{2,+}$, Chen Xu ${ }^{1,3,+}$, Ali Movahedi ${ }^{1,+}\left(\mathbb{D}\right.$, Weibo Sun ${ }^{1}$, Dawei Li ${ }^{1}$ \\ and Qiang Zhuge ${ }^{1, * \mathbb{D}}$ \\ 1 Co-Innovation Center for Sustainable Forestry in Southern China, Key Laboratory of Forest Genetics \& \\ Biotechnology, Ministry of Education, College of Biology and the Environment, Nanjing Forestry University, \\ Nanjing 210037, China; 15850682752@163.com (H.W.); xuchenidea@hotmail.com (C.X.); \\ ali_movahedi@njfu.edu.cn (A.M.); czswb@njfu.edu.cn (W.S.); dwli@njfu.edu.cn (D.L.) \\ 2 Jiangsu Academy of Forestry, Nanjing 211153, China; zjwin718@126.com \\ 3 Jiangsu Provincial Key Construction Laboratory of Special Biomass Resource Utilization, Nanjing Key \\ Laboratory of Quality and Safety of Agricultural Products, Nanjing Xiaozhuang University, \\ Nanjing 211171, China \\ * Correspondence: qzhuge@njfu.edu.cn; Fax: +86-25-8542-8701 \\ + These authors contributed equally to this work.
}

Received: 12 November 2019; Accepted: 25 December 2019; Published: 27 December 2019

check for updates

\begin{abstract}
Interferon gamma-induced lysosomal thiol reductase (GILT) is abundantly expressed in antigen-presenting cells and participates in the treatment and presentation of antigens by major histocompatibility complex II. Also, GILT catalyzes the reduction of disulfide bonds, which plays an important role in cellular immunity. (1) Background: At present, the studies of GILT have mainly focused on animals. In plants, GILT homologous gene (Arabidopsis thaliana OSH1: AtOSH1) was discovered in the forward screen of mutants with compromised responses to sulphur nutrition. However, the complete properties and functions of poplar OSH1 are unclear. In addition, $\mathrm{CdCl}_{2}$ stress is swiftly engulfing the limited land resources on which humans depend, restricting agricultural production. (2) Methods: A prokaryotic expression system was used to produce recombinant PtOSH1 protein, and Western blotting was performed to identify its activity. In addition, a simplified version of the floral-dip method was used to transform A. thaliana. (3) Results: Here, we describe the identification and characterization of OSH1 from Populus trichocarpa. The deduced PtOSH1 sequence contained CQHGX2ECX2NX4C and CXXC motifs. The transcript level of PtOSH1 was increased by cadmium (Cd) treatment. In addition, recombinant PtOSH1 reduced disulfide bonds. A stress assay showed that PtOSH1-overexpressing (OE) A. thaliana lines had greater resistance to Cd than wild-type (WT) plants. Also, the activities of superoxide dismutase (SOD), peroxidase (POD), and catalase (CAT) in PtOSH1-OE plants were significantly higher than those in WT A. thaliana. These results indicate that PtOSH1 likely plays an important role in the response to $\mathrm{Cd}$ by regulating the reactive oxygen species (ROS)-scavenging system. (4) Conclusions: PtOSH1 catalyzes the reduction of disulfide bonds and behaves as a sulfhydryl reductase under acidic conditions. The overexpression of PtOSH1 in A. thaliana promoted root development, fresh weight, and dry weight; upregulated the expression levels of ROS scavenging-related genes; and improved the activity of antioxidant enzymes, enhancing plant tolerance to cadmium (Cd) stress. This study aimed to provide guidance that will facilitate future studies of the function of PtOSH1 in the response of plants to Cd stress.
\end{abstract}

Keywords: cadmium; disulfide bond; GILT; Populus trichocarpa; PtOSH1; ROS-scavenging system 


\section{Introduction}

Interferon- $\gamma$-inducible lysosomal thiol reductase (GILT) has been discovered in many species [1,2]. The precursor of GILT is a soluble glycoprotein, which enters the lysosome by interacting with the mannose-6-phosphate receptor and is transformed into the mature form by cleavage at the $\mathrm{N}$ - and C-termini [3,4]. In the immune system, GILT participates in the denaturation, renaturation, and reduction of disulfide bonds, which are essential for antigen processing and presentation [2,5]. Also, GILT enhances the efficiency of tyrosinase-related protein 1 (TRP-1) presentation by antigen-presenting cells, thus promoting the activity of $\mathrm{T}$ cells and autoimmunity [6]. In addition, GILT participates in the processing of human leukocyte antigen class II, which is essential for activating CD4+ T cells [7,8]. Moreover, GILT enhances the activity of superoxide dismutase (SOD) 2 and maintains reactive oxygen species (ROS) homeostasis [6,9]. GILT has been studied in animals, but its function in plants is unclear.

As the main source of inorganic pollution in soil and farmland [10,11], cadmium (Cd) affects plant growth and development, membrane permeability, photosynthesis, antioxidant enzymes, macromolecular structure, and metabolism, eventually leading to death $[12,13]$. Cd stress induces ROS production in plants, the accumulation of which hinders photosynthesis and compromises the metalloproteins related to electron transfer, suppressing respiration [14]. Cd toxicity can lead to oxidative stress and protein denaturation, to which plants respond by increasing their ability to remove oxidized proteins, enhancing their antioxidant capacity and synthesis of molecular chaperones, and changing the composition of the cell wall and xylem [15-18]. Superoxidase (SOD), catalase (CAT), peroxidase (POD), and other antioxidant enzymes in plants constitute a ROS-scavenging system, which reduces damage to membranes and facilitates adaptation to adverse environments. In plants, SOD degrades the superoxide anion into $\mathrm{H}_{2} \mathrm{O}_{2}$ and $\mathrm{O}_{2}$, which represents the first defense against ROS; also, POD and CAT oxidize $\mathrm{H}_{2} \mathrm{O}_{2}$, further alleviating oxidative damage [19-21].

Thioredoxin (Trx), which has a similar structure as GILT, has been widely studied [22-27]. Trx has a typical WCGH/PCK active domain, in which two cysteine residues are highly conserved and participate in the catalytic reduction of disulfide bonds of target proteins and the regulation of enzyme activity. The molecular structure of the WCGH/PCK domain is similar to that of CXXC, the active site of GILT, which can catalyze the reduction of disulfide bonds [22]. In redox reactions, Trx in its reduced state contacts the disulfide bond of the target protein through the hydrogen on the sulfhydryl, and transforms its own sulfhydryl into a disulfide bond. At the same time, the disulfide bond on the target protein is disrupted, completing the reduction of Trx [28,29]; GILT-mediated reduction occurs in a similar manner. The biological activity of Trx depends on the redox power of reversible disulfide bonds, which can affect protein activity and homeostasis. Disulfide bonds can stabilize protein conformation, which is important for maintaining the spatial organization of a protein. Trx oxidation-reduction is involved in various physiological and biochemical reactions, including redox balance, antioxidant effects [30], signal transduction [31,32], regulation of transcription factors [33,34], and response to heavy metal stress [35]. Trx can function as an antioxidant to remove ROS or as a repair enzyme to regenerate proteins inactivated by oxidative stress. Treating Chlamydomonas reinhardtii with $100 \mu \mathrm{m}$ $\mathrm{CdCl}_{2}$ caused to increase the expression of Trx [36] and its activity by adding dithiothreitol (DTT). The expression of Trx is not able to activate nicotinamide adenine dinucleotide phosphate-dependent malate dehydrogenase (NADP-MDH). It has been suggested that the Trx heavy metal binding site is related to the WCGH/PCK active domain. In addition, the OSH1 gene (At5g01580) improved transcript levels of endogenous S-responsive genes and led to O-Acetyl-L-Ser concentration in the rosette leaves [37]. These studies provide a new theoretical basis for the characterization of OSH1 from plants.

Poplar is an important tree as a source of industrial raw material and is widely distributed in temperate and cold temperate regions. The availability of its genome sequence [38] has promoted genetic research on poplar. However, no in-depth analysis of the OSH1gene of Populus trichocarpa, the putative product of which catalyzes the reduction of disulfide bonds, has been conducted. Furthermore, the role of OSH1 in resistance to Cd stress is unclear. In this study, we isolated the PtOSH1 
(POPTR_0016s12980) gene from P. trichocarpa. Recombinant PtOSH1 catalyzed the reduction of disulfide bonds. Additionally, the expression of PtOSH1 was high in leaves and roots and responded to Cd. The enhanced resistance to $\mathrm{Cd}$ caused by PtOSH1 may be mediated by the reparation of antioxidant enzymes and promotion of ROS homeostasis.

\section{Materials and Methods}

\subsection{Plant Cultivation, Gene Isolation, and Vector Construction}

Poplar (Populus trichocarpa) and Arabidopsis thaliana were cultivated in half-strength Murashige and Skoog (1/2 MS) medium $\left(23^{\circ} \mathrm{C}\right.$, humidity $74 \%$, and $16 \mathrm{~h}$ light/ $8 \mathrm{~h}$ darkness). The young leaves, mature leaves, stems, roots, and petioles of $P$. trichocarpa were collected (Supplementary Figure S1) and total RNA from different tissues was extracted based on the manufacturer's instructions (Biomiga, San Diego, CA, USA). In addition, P. trichocarpa seedlings treated with $200 \mu \mathrm{M} \mathrm{ABA}, 2 \mathrm{mM} \mathrm{CdCl}$, and $2 \mathrm{mM} \mathrm{H}_{2} \mathrm{O}_{2}$ and $P$. trichocarpa young leaves treated with the different abiotic stresses were collected at $0,2,4,6,8,12,24$, and $48 \mathrm{~h}$. Forward and reverse primers were designed based on the sequence of P. trichocarpa GILT obtained from the National Center for Biotechnology Information, and PtOSH1 was amplified by polymerase chain reaction (PCR). The PCR product was inserted into the PEASY-T3 vector (TransGen Biotech, Beijing, China), which was sequenced by Nanjing Genscript Co. (Nanjing, China). The PCR product with EcoRI and XhoI restriction sites was inserted into the PET-28a vector and the PCR product with $\mathrm{XbaI}$ and BamHI restriction sites was inserted into the PBI121 vector by double digestion and T4 ligation. The primers used are shown in the Supplementary Table S1.

\subsection{Prokaryotic Expression, Purification, and Activity of PtOSH1 In Vitro}

The recombinant plasmid PET-28a-PtOSH1 was transformed into Escherichia coli BL21 (DE3) and cultured in Luria-Bertani (LB) medium. The optical density of E. coli BL21 (DE3) at $600 \mathrm{~nm}$ was determined and the isopropyl $\beta$-D-1-thiogalactopyranoside (IPTG) was added to induce synthesis of recombinant PtOSH1. We evaluated the effect of temperature $\left(37\right.$ and $\left.16{ }^{\circ} \mathrm{C}\right)$ and rotational speed (220 and $110 \mathrm{rpm}$ ) on PtOSH1 synthesis. The PtOSH1 level was determined by 12\% sodium dodecyl sulfate-polyacrylamide gel electrophoresis (SDS-PAGE). A nickel-nitrilotriacetic acid (Ni-NTA)-chelating column was used to purify PtOSH1. The supernatant of recombinant E. coli BL21 (DE3) cultures was added to the column, followed by wash buffer (20 mM Tris- $\mathrm{HCl}, 0.15 \mathrm{M} \mathrm{NaCl}$, and $20 \mathrm{mM}$ imidazole; $\mathrm{pH}$ 8.0) until the absorbance reached baseline, and finally elution buffer (20 $\mathrm{mM}$ Tris- $\mathrm{HCl}, 0.15 \mathrm{M} \mathrm{NaCl}$, and $250 \mathrm{mM}$ imidazole; $\mathrm{pH} 8.0$ ).

To assay PtOSH1 activity, $0.2 \%$ SDS was used to denature immunoglobulin $\mathrm{G}(\mathrm{IgG})$ at $100{ }^{\circ} \mathrm{C}$ for $5 \mathrm{~min}$. Dilution buffer $(50 \mathrm{mM} \mathrm{NaCl}, 0.1 \%$ Triton X-10) was used to dilute the denatured IgG. PtOSH1 was dissolved in enzyme activity solution $(100 \mathrm{mM} \mathrm{NaCl}, 0.1 \%$ Triton $\mathrm{X}-10,50 \mathrm{mM} \mathrm{CH} \mathrm{COONa}$ $25 \mathrm{mM}$ DTT; pH 4.5), and the mixture was incubated at $37^{\circ} \mathrm{C}$ for $10 \mathrm{~min}$ to pre-activate PtOSH1. Also, $10 \mu \mathrm{L}$ of denatured IgG and $100 \mu \mathrm{L}$ of PtOSH1 were incubated at $37^{\circ} \mathrm{C}$ for $1 \mathrm{~h}$ and subjected to non-reducing SDS-PAGE.

\subsection{Overexpression of PtOSH1 in Arabidopsis Thaliana (A. Thaliana)}

The recombinant plasmid PBI121-PtOSH1 was transformed into Agrobacterium tumefaciens GV3101, and subsequently transformed into $A$. thaliana by the floral-dip method [39]. Putative T1 seedlings were screened in $1 / 2$ MS medium containing $50 \mu \mathrm{g} \mathrm{mL}^{-1}$ kanamycin, and the putative plants were grown in soil. Subsequently, the T2 seedlings were screened as above. The DNA and RNA of T2 plants were extracted to confirm the insertion of PtOSH1 into the A. thaliana genome. Three independent biological experiments were performed.

For $\mathrm{CdCl}_{2}$ treatment, wild-type (WT) and PtOSH1-OE $A$. thaliana plants were cultivated in $1 / 2 \mathrm{MS}$ medium, and 1-week-old WT and PtOSH1-OE $A$. thaliana plants were planted in 1/2 MS medium with $0,20,40,60$, and $80 \mu \mathrm{M} \mathrm{CdCl}_{2}$. WT and PtOSH1-OE $A$. thaliana plants were grown in MS medium 
containing 0-80 $\mu \mathrm{M} \mathrm{CdCl}_{2}$ for 20 days, and the root length, fresh weight, and dry weight of WT and PtOSH1-OEs were determined. Three independent biological experiments were performed. In addition, the transcript levels of genes related to ROS scavenging were evaluated in WT and PtOSH1-OEs. A microplate reader (Bio-Rad, Hercules, CA, USA) was used to analyze the CAT, SOD, and POD activities before and after treatment with $60 \mu \mathrm{M} \mathrm{CdCl}_{2}$ based on the protocol of the Nanjing Jiancheng Bioengineering Institute.

\subsection{Polymerse Chain Reaction (PCR) and Quantitative Reverse Transcription-PCR}

PCR was performed as follows: $95^{\circ} \mathrm{C}$ for $5 \mathrm{~min} ; 35$ cycles of $95^{\circ} \mathrm{C}$ for $30 \mathrm{~s}, 58^{\circ} \mathrm{C}$ for $40 \mathrm{~s}$, and $72{ }^{\circ} \mathrm{C}$ for $30 \mathrm{~s}$; and $72{ }^{\circ} \mathrm{C}$ for $10 \mathrm{~min}$. SYBR Green Mix (Roche, Basel, Switzerland) was added to the PCR mixture, and quantitative reverse transcription-PCR (qRT-PCR) was conducted as follows: initial incubation at $95^{\circ} \mathrm{C}$ for $5 \mathrm{~min} ; 40$ cycles of $95^{\circ} \mathrm{C}$ for $30 \mathrm{~s}$ and $60^{\circ} \mathrm{C}$ for $30 \mathrm{~s}$; and $72{ }^{\circ} \mathrm{C}$ for $30 \mathrm{~s}$. $\beta$-Actin of $P$. trichocarpa and $A$. thaliana were used as internal controls. Three independent biological experiments were analyzed with three technical repeats. The primers used are shown in the Supplementary Table S1.

\section{Results}

\subsection{Molecular Characterization of a Poplar OSH1}

We cloned an OSH1 from P. trichocarpa. The open reading frame (ORF) of PtOSH1 (POPTR_0016s12980) contained 813 nucleotides and encoded 270 amino acids. The predicted signal peptide of PtOSH1 was 'MGSSPLLSFLVLTSLVVLFVTPSHS' and located at the N-terminus of PtOSH1, this petide was necessary for its transportation to the lysosome. (Supplementary Figure S2). Also, PtOSH1 was predicted to be located in the lysosome. The amino acid sequence of PtOSH1 had two characteristic motifs (CXXC and CQHGX ${ }_{2} \mathrm{ECX}_{2} \mathrm{NX}_{4} \mathrm{C}$ ), and two glycosylation sites (NNT and NTS) (Supplementary Figure S2). We speculated that PtOSH1 had sulfhydryl reductase activity. The homology of PtOSH1 with GILTs from other species was analyzed using Clustal Omega and BOXSHADE software. All of the GILTs had the characteristic CXXC and CQHGX ${ }_{2} \mathrm{ECX}_{2} \mathrm{NX}_{4} \mathrm{C}$ motifs and ten highly conserved cysteine residues (Supplementary Figure S3), as well as sulfhydryl reductase activity, suggesting that PtOSH1 also has sulfhydryl reductase activity.

OsAK071633, OsAK106050, AT1G07080, AT4G12870, At4G12890, AT4G12900, AT4G12960, AT5G01580, CsXP_010475460, EgXP_010937929, NtXP_016471791, POPTR_0016s12980 were included in a phylogenetic tree constructed using MEGA 5.0 software. The OsAK071633, OsAK106050, AT1G07080, CsXP_010475460, EgXP_010937929, NtXP_016471791, POPTR_0016s12980 formed a large branch, suggesting close relationships among OsAK071633, OsAK106050, AT1G07080, CsXP_010475460, EgXP_010937929, NtXP_016471791, POPTR_0016s12980 (Figure 1). In addition, the tertiary structures of HoGILT, AtOSH1 and PtOSH1 were predicted using the online software tools of the SWISS-MODEL server (http://www.expasy.org/swissmod/SWISS-MODEL.html). Three-dimensional models are constructed according to multiple-threading alignments by LOMETS (https://zhanglab.ccmb.med. umich.edu/LOMETS/). A homology analysis showed that POPTR_0016s12980 differed from the HoNP_006323 and AT1G07080, but had a similar three-dimensional (3D) structure. The CXXC and $\mathrm{CQHGX}_{2} \mathrm{ECX}_{2} \mathrm{NX}_{4} \mathrm{C}$ motifs were present in the same position in the 3D structure of POPTR_0016s12980, AT1G07080 and HoGILT (Figure 2). Therefore, POPTR_0016s12980 may have similar biological functions to HoNP_006323. 


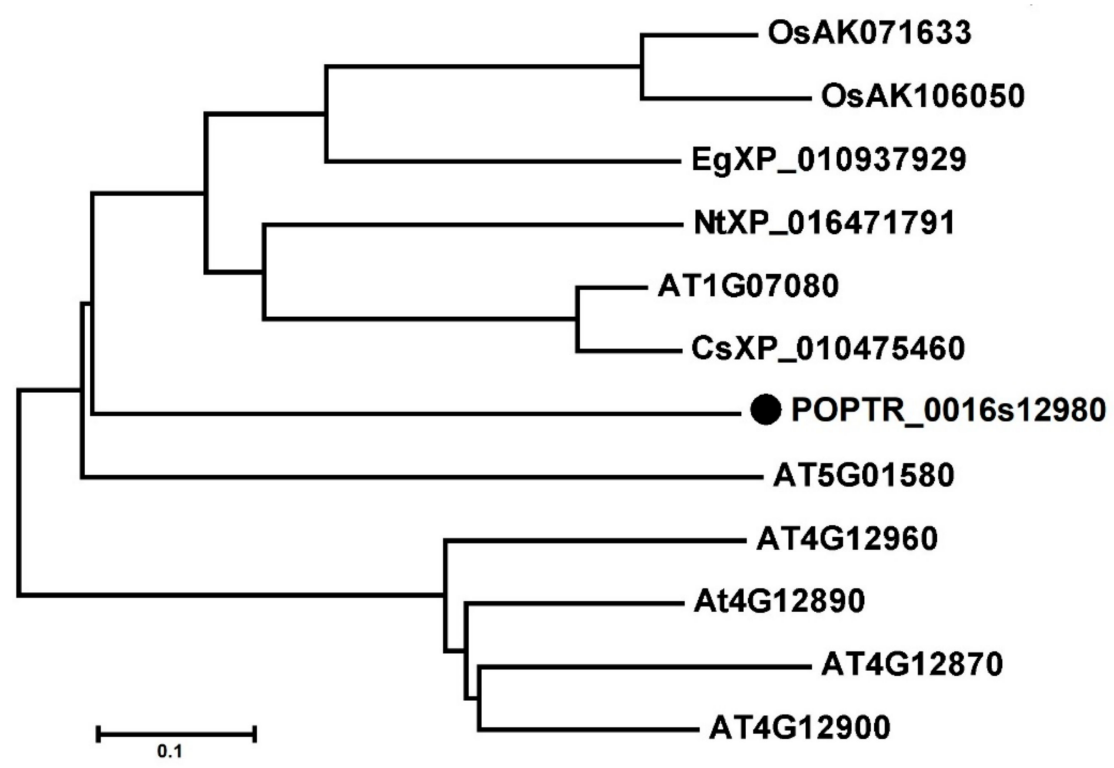

Figure 1. The phylogenetic tree analysis of OSH1 proteins. Translated amino acid sequence of POPTR_0016s12980 was compared using the BLASTP search program. GenBank accession number is preceded by a species identifier. Pt, Populus trichocarpa; At, Arabidopsis thaliana; Os, Oryza sativa; Nt, Nicotiana tabacum; Cs, Camelina sativa; Eg, Elaeis guineensis.
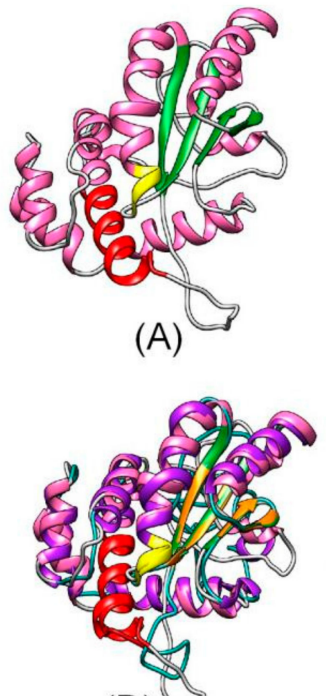

(D)

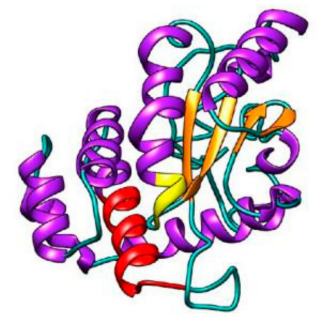

(B)

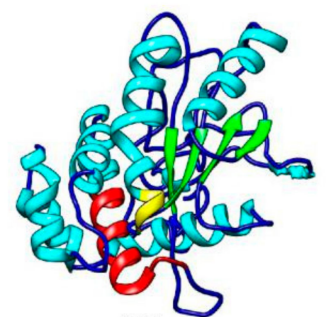

(C)

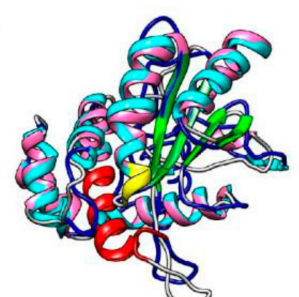

(E)

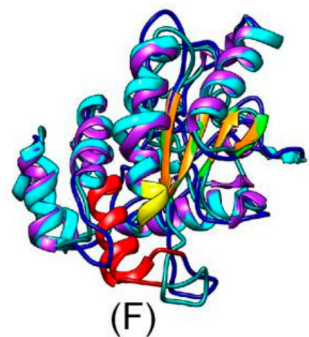

(F)

Figure 2. Homology of the predicted tertiary structures of HoNP_006323 (A) H. sapiens (NP_006323.2), and homology of the predicted tertiary structures of AT1G07080 (B), POPTR_0016s12980 (C), HoNP_006323.2 and AT1G07080 (D), HoNP_006323 and POPTR_0016s12980 (E), and POPTR_0016s12980 and AT1G07080 (F). Red, CXXC motif; yellow, $\mathrm{CQHGX}{ }_{2} \mathrm{ECX}_{2} \mathrm{NX}_{4} \mathrm{C}$ motif. Pt, P. trichocarpa; $\mathrm{At}$, $A$. thaliana; $\mathrm{Ho}$, Homo sapiens.

\subsection{Transcript Levels of PtOSH1 in Tissues and Under $\mathrm{Cd}^{2+}$ Stress}

The highest transcript level of PtOSH1 was in young and mature leaves, followed by roots, and the lowest was in petioles (Figure 3A). Treatment with $2 \mathrm{mM} \mathrm{CdCl}_{2}$ significantly increased the transcript level of PtOSH1 from 6 to $48 \mathrm{~h}$, with a peak at $12 \mathrm{~h}$ (Figure 3B). Treatment with $200 \mu \mathrm{M}$ ABA caused significant accumulation of PtOSH1 mRNA from 6 to $24 \mathrm{~h}$ (Figure 3C). The expression of PtOSH1 was enhanced from 1 to $24 \mathrm{~h}$ of $2 \mathrm{mM} \mathrm{H}_{2} \mathrm{O}_{2}$ treatment (Figure 3D). Plant roots and leaves absorb exogenous substances. During plant growth and development, nutrient transport involves various signaling 
pathways, in which oxidoreductases play an important role. Therefore, the differential expression of GILT in different tissues may be related to normal physiological functions.
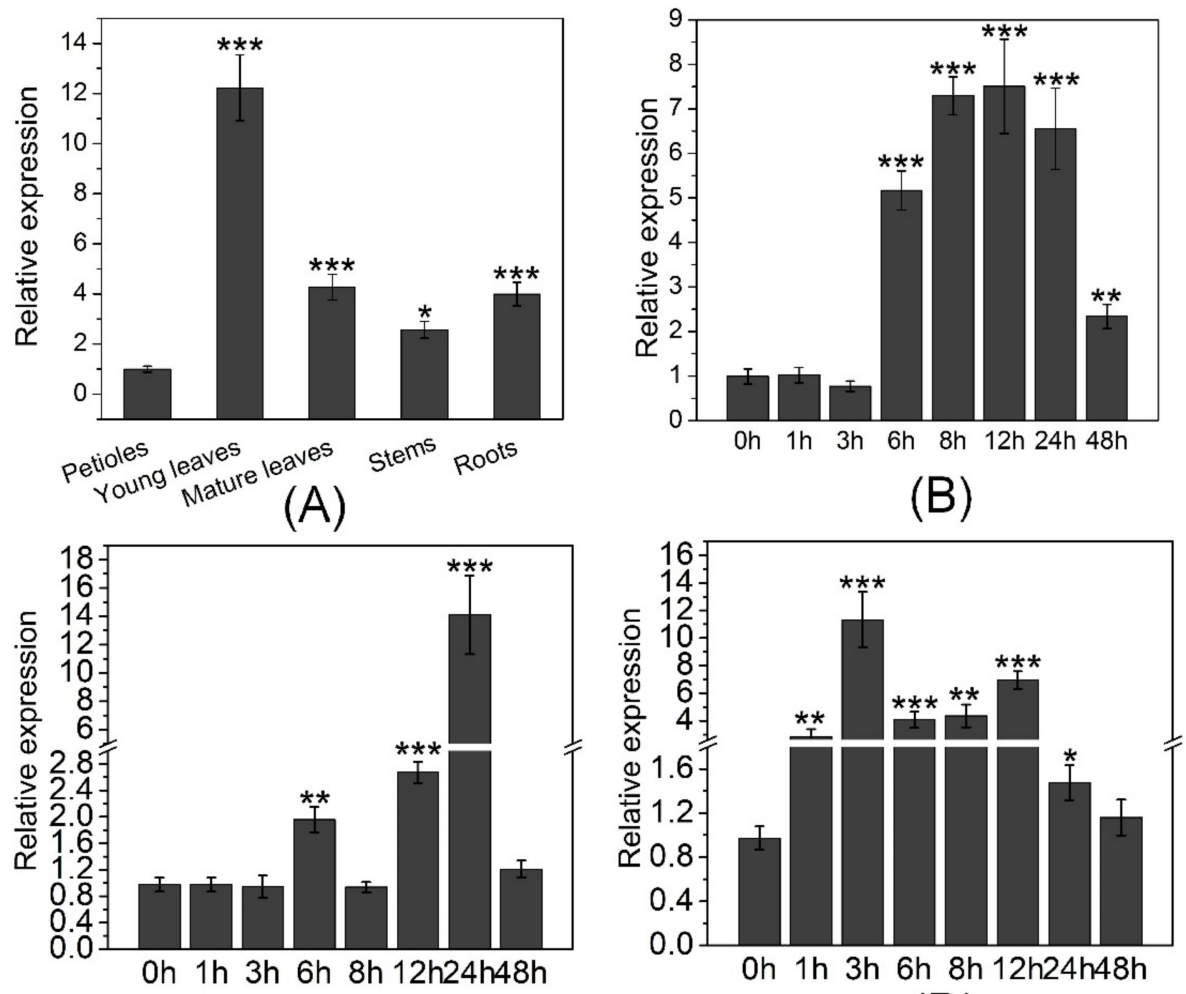

(C)

(D)

Figure 3. The identification of PtOSH1 mRNA expression level based on the quantitative reverse transcription polymerase chain reaction (qRT-PCR). (A) The mRNA transcript levels of PtOSH1 in various tissues. (B) The mRNA transcript level of PtOSH1 in response to Cd stress. (C) The mRNA transcript level of PtOSH1 in response to ABA stress. (D) The mRNA transcript level of PtOSH1 in response to $\mathrm{H}_{2} \mathrm{O}_{2}$ stress. Three independent biological experiments were performed with three technical repeats. One-way analysis of variance (ANOVA) and Tukey's test were used to evaluate significant differences. Data are $2^{-\Delta \Delta C t}$ levels relative to the petiole and normalized to that of PtActin. Vertical bars represent the means \pm standard deviation $(\mathrm{SD}, \mathrm{n}=3) .{ }^{*}$, Significant difference at $p<0.05$; **, Significant difference at $p<0.01 ; * *$, significant difference at $p<0.001$.

\subsection{Expression, Purification, and Functional Analysis of Recombinant PtOSH1}

The ORF of PtOSH1 was cloned into the plasmid PET-28a between the EcoRI and XhoI sites. Analysis by $12 \%$ SDS-PAGE showed that the production of recombinant PtOSH1 was induced by $1 \mathrm{mM}$ IPTG at $110 \mathrm{rpm}$ at $16^{\circ} \mathrm{C}$, but not at $37^{\circ} \mathrm{C}$ (Figure $4 \mathrm{~A}$ ). Recombinant PtOSH1 was purified using $\mathrm{Ni}-\mathrm{IDA}$ resin (Figure $4 \mathrm{~B}$ ) and Western blotting showed that recombinant PtOSH1 was specifically recognized by rabbit antiserum (Figure $4 \mathrm{~B}$ ).

Arunachalam et al. [3] showed that GILT proteins can catalyze the reduction of disulfide bonds and exhibit sulfhydryl reductase activity under acidic conditions. We used human IgG as a substrate to assay the activity with PtOSH1 in vitro. The disulfide bond of IgG was intact (lane 2) following treatment of DTT (Figure 4C). In the absence of $25 \mathrm{mM}$ DTT, the disulfide bond (lane 6) of IgG was intact at $\mathrm{pH} 4.5$ and 7.0. At $10 \mathrm{mM}$ DTT, the disulfide bond (lane 5) was broken at $\mathrm{pH} 7.0$ but not $\mathrm{pH}$ 4.5. Activated PtOSH1 cleaved IgG into heavy and light chains (lane 3), indicating that recombinant PtOSH1 catalyzed the reduction of the disulfide bond, in which DTT at a low concentration acted as a cofactor. 


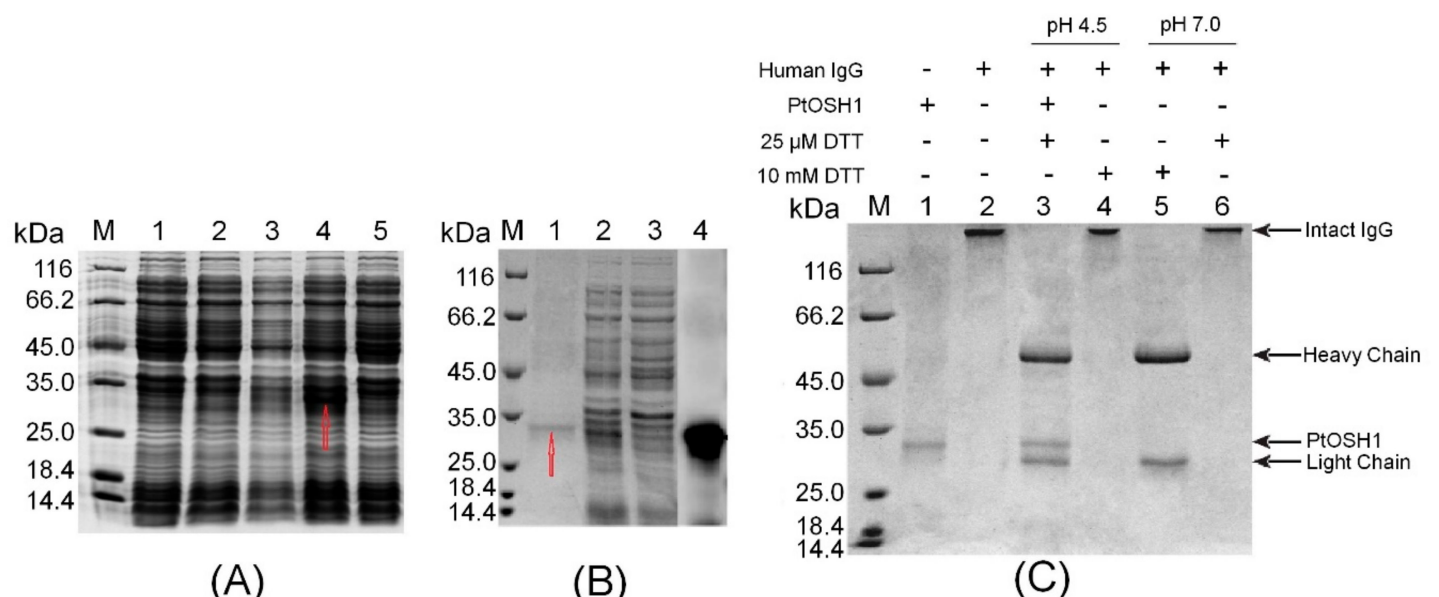

Figure 4. The identification of sulfhydryl reductase activity in vitro. (A) Analysis of recombinant PtOSH1 protein expression. Lane M, molecular mass marker; lane 1, control; lane 2, recombinant $E$. coli $B L 21$ (DE3) incubated at $220 \mathrm{rpm}$ at $37^{\circ} \mathrm{C}$ with induction by $1 \mathrm{mM}$ isopropyl $\beta$-D-1-thiogalactopyranoside (IPTG); lane 3, recombinant E. coli BL21 (DE3) incubated at $110 \mathrm{rpm}$ at $37^{\circ} \mathrm{C}$ with induction by $1 \mathrm{mM}$ IPTG; lane 4, recombinant E. coli BL21 (DE3) incubated at $110 \mathrm{rpm}$ at $16^{\circ} \mathrm{C}$ with induction by $1 \mathrm{mM}$ IPTG; and lane 5, recombinant E. coli BL21 (DE3) incubated at $220 \mathrm{rpm}$ at $37^{\circ} \mathrm{C}$ with induction by $1 \mathrm{mM}$ IPTG. (B) Purification and western blot analysis of recombinant PtOSH1 protein. Lane M, molecular mass marker; lane 1, eluate; lanes 2-3, flow-through; lane 4, Western blot. (C) Analysis of PtOSH1 protein activity in vitro. Lane M, molecular mass marker; lane 1, recombinant PtOSH1 protein; lane 2, human IgG; lane 3, human IgG incubated with PtOSH1 protein ( $\mathrm{pH} 4.5$ ); lane 4, human IgG incubated with $10 \mathrm{mM}$ dithiothreitol (DTT, pH 4.5); lane 5, human IgG incubated with $10 \mathrm{mM}$ DTT (pH 7.0); and lane 6, human IgG incubated with $25 \mu \mathrm{M}$ DTT (pH 7.0).

\subsection{Characterization of Transgenic A. Thaliana Lines}

To further study the function of PtOSH1 in transgenic A. thaliana lines, the PBI121-PtOSH1 vector was introduced into WT A. thaliana. Subsequently, PtOSH1-OE lines were obtained (Supplementary Figure S4). The total genome of the WT and PtOSH1-OE lines was extracted and amplified by PCR. The lanes of the PtOSH1-OE lines, but not that of the WT, had the expected band (Supplementary Figure S5A). Also, qRT-PCR analysis showed that PtOSH1 was stably expressed in A. thaliana (Supplementary Figure S5B). In addition, the transcript levels of Arabidopsis homologs At1G07080 and At5G01580 were identified. The expression of At1G07080 in PtOSH1-OE lines was increased significantly $(p<0.05)$ (Supplementary Figure S6A). However, there are no significant difference in expression of At5G01580 between WT and PtOSH1-OE lines (Supplementary Figure S6B).

\subsection{Response of Transgenic Plants to $\mathrm{Cd}^{2+}$ Stress}

WT and PtOSH1-OE A. thaliana plants were grown in 1/2 MS medium containing 20, 40, 60, and $80 \mu \mathrm{M} \mathrm{CdCl}_{2}$ and their growth was evaluated after 20 days. The growth of WT and transgenic A. thaliana lines was little affected by $20 \mu \mathrm{M} \mathrm{CdCl}_{2}$ (Figure $5 \mathrm{~A}, \mathrm{~B}$ and Figure 6). When exposed to 40-60 $\mu \mathrm{M} \mathrm{CdCl}_{2}$, the root length and biomass of plants decreased significantly, and the root length and biomass of the PtOSH1-OE A. thaliana lines were significantly higher than those of WT A. thaliana (Figure 5C,D and Figure 6), suggesting that transgenic plants have a growth advantage. At $80 \mu \mathrm{MCdCl}_{2}$, the germination and growth of $A$. thaliana were inhibited; leaf yellowing, root length, and the fresh weight of the PtOSH1-OE A. thaliana lines were significantly higher than those of WT A. thaliana; and the number of lateral roots increased significantly (Figures 5E and 6). Therefore, PtOSH1-like transgenic A. thaliana plants showed greater tolerance to $\mathrm{CdCl}_{2}$ stress than did WT plants. 


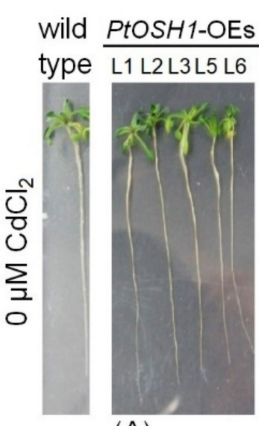

(A)

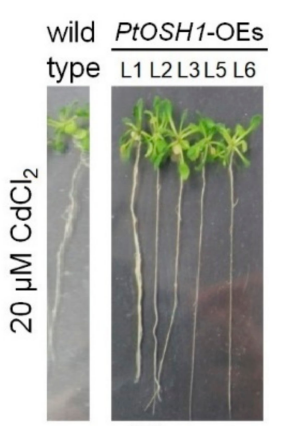

(B)

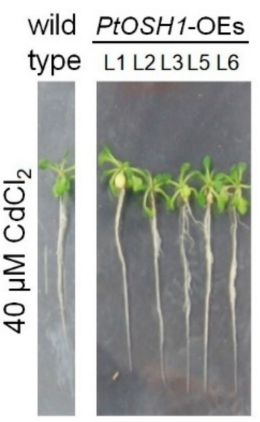

(C)

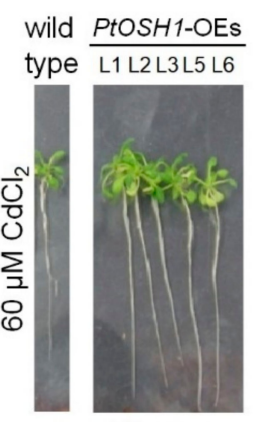

(D)

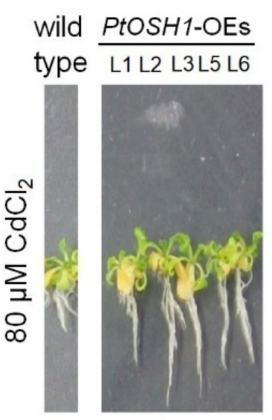

$(\mathrm{E})$

Figure 5. Phenotypic analysis of wild-type (WT) and transgenic A. thaliana lines (Line1 (L1), L2, L3, L5, L6) treated in $0 \mu \mathrm{M} \mathrm{Cd}(\mathbf{A}), 20 \mu \mathrm{M} \mathrm{Cd}(\mathbf{B}), 40 \mu \mathrm{M} \mathrm{Cd}(\mathbf{C}), 60 \mu \mathrm{M} \mathrm{Cd}(\mathbf{D})$, and $80 \mu \mathrm{M} \mathrm{Cd}(\mathbf{E})$. Three independent biological experiments were performed.

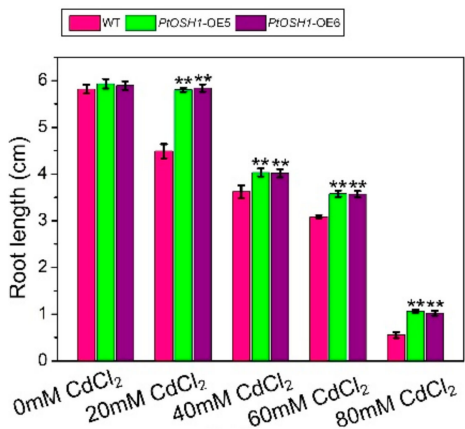

(A)

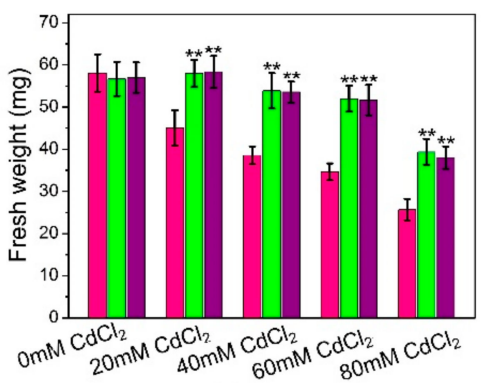

(B)

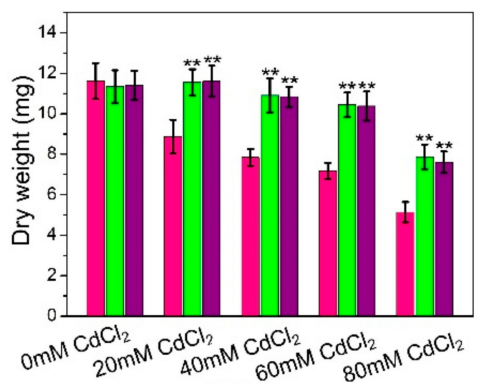

(C)

Figure 6. Tolerance of WT A. thaliana and PtOSH1-OE A. thaliana lines to Cd stress. (A) Root length of WT and PtOSH1-OE A. thaliana lines under Cd stress. (B) Fresh weight of WT and PtOSH1-OE A. thaliana lines under Cd stress. (C) Dry weight of WT and PtOSH1-OE A. thaliana lines under Cd stress. Three independent biological experiments were performed. One-way ANOVA and Tukey's test were used to evaluate significant differences. Vertical bars represent the means $\pm \operatorname{SD}(n=3)$. ${ }^{* *}$, Significant difference at $p<0.01$.

Cd stress triggers the production of ROS in plants, the accumulation of which hinders photosynthesis. In addition, the metalloproteins related to electron transfer in plants are compromised by $\mathrm{Cd}$, disrupting respiration [12]. The plant antioxidant defense system eliminates ROS to prevent the damage caused by oxidative stress [40]. qRT-PCR analysis showed that the expression levels of ascorbate peroxidase (APX), CAT, glutathione S-transferase (GST), POD, and SOD in WT and PtOSH1-OE plants were not significantly different under normal conditions but were higher in PtOSH1-OE plants than in WT plants under $\mathrm{CdCl}_{2}$ stress (Figure 7). To determine whether overexpression of $\mathrm{PtOSH} 1$ increased tolerance to $\mathrm{CdCl}_{2}$ stress, we analyzed the activities of POD, $\mathrm{SOD}$, and CAT under $60 \mu \mathrm{M} \mathrm{CdCl}_{2}$ stress. Under normal conditions, PtOSH1-OE A. thaliana lines had slightly higher activities of POD, SOD, and CAT than WT A. thaliana; however, PtOSH1-OE A. thaliana lines had significantly higher activities of POD, SOD, and CAT than WT A. thaliana after 20 days of $\mathrm{CdCl}_{2}$ stress (Figure 8). Therefore, PtOSH1 promotes ROS scavenging by POD, SOD, and CAT to alleviate the oxidative damage to membranes caused by $\mathrm{CdCl}_{2}$ stress, increasing the tolerance to $\mathrm{CdCl}_{2}$ of the PtOSH1-OE plants. 


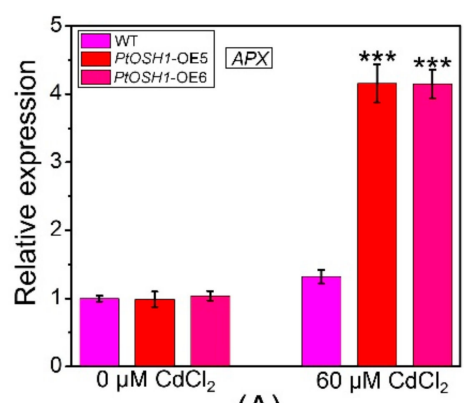

(A)

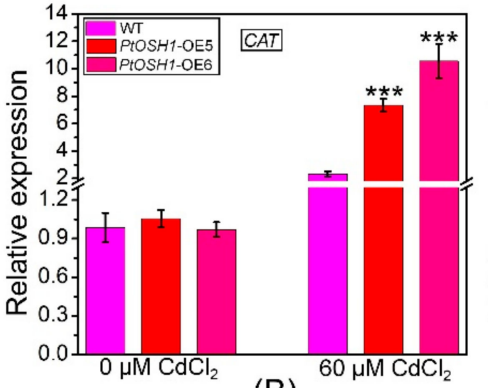

(B)

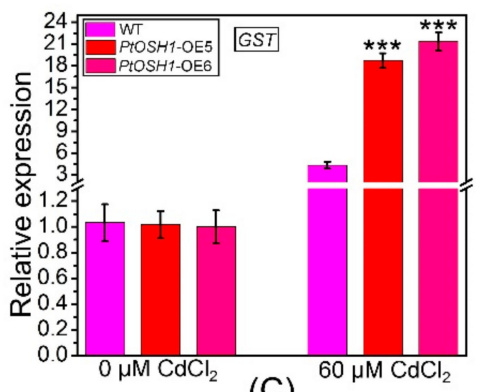

(C)

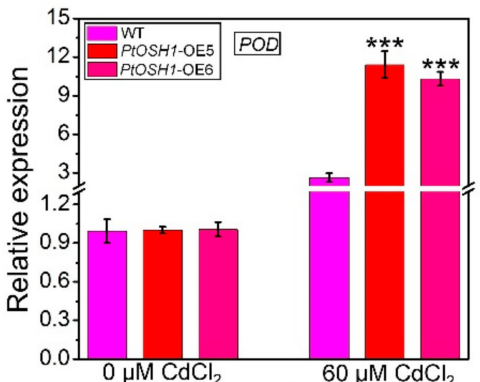

(D)

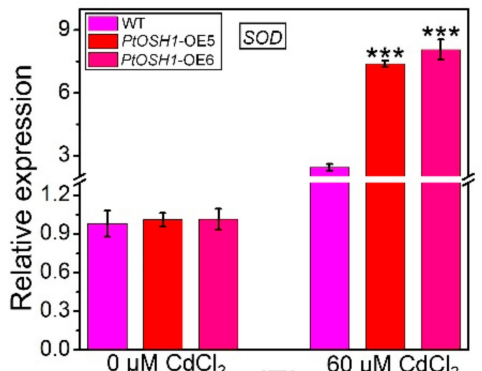

(E)

Figure 7. Transcript levels of ascorbate peroxidase $(A P X)(\mathbf{A})$, catalase $(C A T)(\mathbf{B})$, glutathione S-transferase $(G S T)(\mathbf{C})$, peroxidase $(P O D)(\mathbf{D})$, and superoxide dismutase $(S O D)(\mathbf{E})$ before and after exposure to $60 \mu \mathrm{M} \mathrm{Cd}^{2+}$. Data are $2^{-\Delta \Delta \mathrm{Ct}}$ levels relative to WT plants and normalized to the transcript level of AtActin. Three independent biological experiments were performed with three technical repeats. One-way ANOVA and Tukey's test were used to evaluate significant differences. Vertical bars represent the means $\pm \mathrm{SD}(\mathrm{n}=3)$. ${ }^{* * *}$, Significant difference at $p<0.001$. Accession numbers: APX (NM_119666.4), CAT (NM_119675.4), GST (NM_128499.5), POD (NM_119917.3), and SOD (NM_001084025.1).

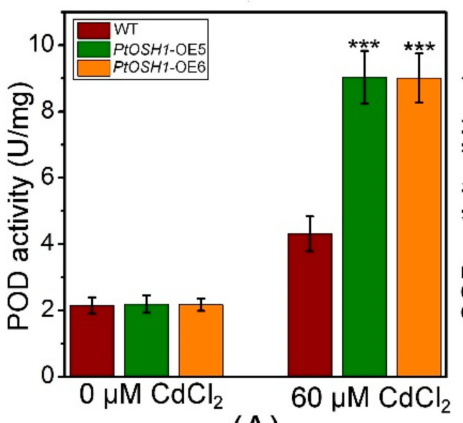

(A)

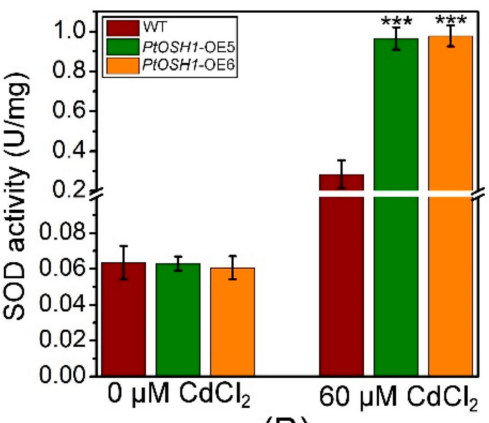

(B)

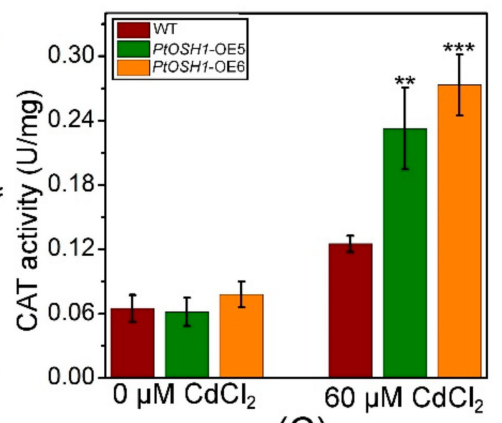

(C)

Figure 8. Activities of POD (A), SOD (B), and CAT (C) in WT and PtOSH1-OE A. thaliana lines before and after exposure to $60 \mu \mathrm{M} \mathrm{Cd}^{2+}$. Three independent biological experiments were performed with three technical repeats. One-way ANOVA and Tukey's test were used to evaluate significant differences. Vertical bars represent the means $\pm \operatorname{SD}(n=3)$. ${ }^{* *}$, Significant difference at $p<0.01 ;{ }^{* * *}$, significant difference at $p<0.001$.

\section{Discussion}

Research on GILT has focused on animals, including human [1], mouse [41], chicken [42], zebrafish [43], amphioxus [44], pig [45], large yellow croaker [46], and fruit bat [47]. These GILTs have the CXXC/S functional domain, which is similar to the WCGH/PCK domain of the thioredoxin family [41,45]. In addition, GILT has a signature sequence $\left(\mathrm{CQHGX}_{2} \mathrm{CX}_{2} \mathrm{NX}_{4} \mathrm{C}\right)$, multiple $\mathrm{N}$-glycosylation sites, and 10-11 conserved cysteine residues [48]. However, the function of plant GILTs was unknown. In this study, we characterized PtOSH1 of P. trichocarpa. PtOSH1 has the same motifs and a similar structure to human GILT, indicating that these proteins have similar functions. 
During the processing and presentation of antigens, disulfide bonds are denatured, renatured, and reduced; the latter is particularly important. GILT is the only reductase that catalyzes the reduction of disulfide bonds at low $\mathrm{pH}$ and exhibits high activity in the acidic lysosome [49-51]. Ohkama-Ohtsu et al. [37] demonstrated that recombinant At5g01580 protein expressed by E. coli had thiol reductase activity under neutral conditions. However, the GILT of humans has the highest thiol reductase activity at acidic conditions [3]. In this study, we demonstrated that PtOSH1 cleaves IgG into heavy and light chains by catalyzing the reduction of disulfide bonds under neutral conditions. PtOSH1-catalyzed reduction of disulfide bonds may alter the structure and function of proteins in poplar. The reduction of disulfide bonds in some proteins restores their normal physiological function. Therefore, PtOSH1 may affect homeostasis of poplar by catalyzing the reduction of disulfide bonds.

Plants under stress conditions produce large amounts of ROS, including superoxide anions and free radicals [52,53]. To decrease the resulting oxidative damage, the antioxidant systems of plants not only scavenge ROS and limit their production but also repair oxidative damage [54,55]. Thioredoxin reductase (Trx) has a WCGH/PCK domain, which catalyzes the reduction of disulfide bonds and is involved in a variety of biochemical reactions [56], including regulation of redox potential, antioxidants, signal-transduction pathways, transcription factors, and the response to heavy metal stress $[30,57,58]$. In this study, the expression of $\mathrm{PtOSH1}$ was upregulated by $\mathrm{CdCl}_{2}$ treatment. Also, overexpression of PtOSH1 enhanced the resistance of $A$. thaliana to $\mathrm{CdCl}_{2}$ stress. These findings implicate PtOSH1 in the response to $\mathrm{CdCl}_{2}$ stress. Trx scavenges ROS and activates proteins inactivated by oxidative stress, which are important for maintaining the physiological function of cells under oxidative stress [59-61]. In WT and PtOSH1-OE plants, APX, CAT, GST, POD, and SOD transcript levels were increased by $\mathrm{CdCl}_{2}$ stress, and the magnitude of the increase was higher in PtOSH1-OE plants than in WT plants. In addition, the activities of SOD, POD, and CAT were higher in PtOSH1-OE $A$. thaliana lines than in WT A. thaliana. Therefore, PtOSH1 might be important for defense against $\mathrm{CdCl}_{2}$ stress. However, the underlying mechanism is unknown; therefore, a mechanistic investigation of the antioxidant activity of PtOSH1 is required to determine its effect on ROS.

Previous studies showed that $\mathrm{Cd}$ poisoning can lead to oxidative stress and protein denaturation in plants. However, plants have defense mechanisms to alleviate the damage from oxidative stress, including increasing the ability to remove oxidized proteins, improving the synthesis of antioxidant molecules and molecular chaperones, and changing the composition of plant cell walls and xylem sediments [17]. In addition, Salt et al. [62] found that Cd was mainly distributed in the leaf epidermis and epidermal hairs of mustard. $\mathrm{Cd}$ in plants may be a defense mechanism to prevent damage because the substances needed for photosynthesis, growth, and development are mainly in mesophyll cells, and leaf epidermis and epidermal hairs play a role in isolation and protection. Due to the lack of GILT, the activity and stability of SOD2 were decreased in the animal cells. Recombinant GILT improved the activity and stability of SOD2 and maintained a relatively steady level of ROS; thus, GILT promotes maintenance of the redox state in cells. GILT also promotes intracellular oxidative stress in cells, which can accelerate autophagy and decompose damaged mitochondria [9]. In this study, the transcript level of PtOSH1 was improved under Cd treatment, and PtOSH1 catalyzed the reduction of disulfide bonds. Two cysteines are located in active sites of GILT. One cysteine is nucleophilic; it attacks the disulfide bond on the substrate to form a disulfide compound and intermediate substrate, and then the two cysteines on GILT carry out an internal attack to cause the substrate to escape so that the disulfide bond of the substrate is opened [51]. GILT catalyzes disulfide reduction, which is accompanied by changes in protein structure and function in cells. Some disulfide bonds can be reduced to restore their normal physiological functions. GILT regulates ROS homeostasis by repairing antioxidant enzymes and ultimately maintains the redox state in cells. Together, our results demonstrate that PtOSH1 is essential for $\mathrm{Cd}$ stress and that PtOSH1 may restore antioxidant enzymes by catalyzing disulfide reduction as well as regulating the steady state of ROS. 


\section{Conclusions}

In conclusion, when plants are stressed by heavy metals, the activity of the antioxidant system in plants is improved, and antioxidant enzymes can scavenge ROS and play a protective role. When stressed by heavy metals for a long time, the antioxidant enzyme system of plants is destroyed, and plants are poisoned by ROS. In addition, although GILT from animals has been well characterized and its function evaluated, there have been fewer studies of the function of GILT-like in plants. Therefore, a more thorough understanding of GILT, including how it is regulated, is important for maintaining the mechanism of ROS underlying Cd treatment. In this study, we isolated PtOSH1 from $P$. trichocarpa, which can respond to Cd treatment; transgenic experiments in $A$. thaliana provided further evidence related to the response to Cd stress. Collectively, our results demonstrate that PtOSH1 catalyzes the reduction of disulfide bonds and may repair the antioxidant enzymes resulting from $\mathrm{Cd}$ stress and regulate the ROS-scavenging system, which is important for the steady state of plant cells.

Supplementary Materials: The following are available online at http://www.mdpi.com/2073-4409/9/1/76/s1, Figure S1: Samples were extracted from young and mature leaves, stems, petioles, and roots, respectively. Figure S2: Nucleic acid and amino acid sequences of PtOSH1. Double solid lines, predicted signal peptide; gray shading, CXXC motif; rectangle, CQHGX2ECX2NX4C motif; blue ellipses, glycosylation sites; *, termination codon. Figure S3: Multiple alignment of GILT proteins and OSH1 proteins from the indicated species. Accession numbers: At1G07080, POPTR_0016s12980, DmNP_650287, DmAAF56157, DmNP_651165, DrNP_001006057, DrXP_693944,GgXP_418246, HsNP_006323, and MmNP_075552. Rectangles, CXXC and CQHGX2ECX2NX4C motifs; ${ }^{*}, 10$ highly conserved cysteine residues. At, A. thaliana; Pt, P. trichocarpa; Dm, D. melanogaster; Dr, D. rerio; Gg, G. gallus; Hs, H. sapiens; Mm, M. musculus. Figure S4: Screening for A. thaliana lines overexpressing PtOSH1. The T1 generation (arrows) represents putative transgenic plants and the T1 generation (circles) represents albino or yellowed plants. Figure S5: Identification of putative A. thaliana plants overexpressing PtOSH1. (A) PCR analysis of PtOSH1 in WT and PtOSH1-OE A. thaliana lines. Lane M, 2K marker; lane 1, positive control; lanes 2-6, transgenic lines 1-5, respectively; and lane 7, negative control. (B) Identification of PtOSH1 expression level in WT and PtOSH1-OE $A$. thaliana lines. Three independent experiments were performed. Vertical bars represent the mean $\pm \operatorname{SD}(n=3)$. *, Significant difference at $p<0.05 ; * * *$, significant difference at $p<0.001$. Figure S6: Transcript levels of At1G07080 (A) and At5G01580 (B) in WT and PtOSH1-OE A. thaliana lines. Three independent experiments were performed. Vertical bars represent the mean $\pm \operatorname{SD}(n=3)$. ${ }^{*}$, Significant difference at $p<0.05$. Table S1: The primers used in this study.

Author Contributions: H.W., J.Z., C.X., and A.M. designed, carried out and wrote the manuscript. H.W., J.Z., C.X., and A.M. W.S., and D.L. modified the manuscript. J.Z. and Q.Z. supervised this project. J.Z. and Q.Z. funded this project. All authors have read and agreed to the published version of the manuscript.

Funding: This work was supported by the Research Program of Jiangsu Academy of Forestry (BM2018022-01) and the Priority Academic Program Development of Jiangsu Higher Education Institutions.

Acknowledgments: We thank Tsuyoshi Nakagawa (Research Institute of Molecular Genetics Shimane University) for guiding the transformation of Arabidopsis thaliana. We also thank Kees Venema (EEZ, CSIC, and Granada, Spain) for suggestion on 3D structure analysis.

Conflicts of Interest: The authors declare conflicts of interest.

\section{References}

1. Luster, A.D.; Weinshank, R.L.; Feinman, R.; Ravetch, J.V. Molecular and biochemical characterization of a novel gamma-interferon-inducible protein. J. Biol. Chem. 1988, 263, 12036-12043. [PubMed]

2. Sigal, L.J.; Crotty, S.; Andino, R.; Rock, K.L. Cytotoxic T-cell immunity to virus-infected non-haematopoietic cells requires presentation of exogenous antigen. Nature 1999, 398, 77. [CrossRef] [PubMed]

3. Arunachalam, B.; Phan, U.T.; Geuze, H.J.; Cresswell, P. Enzymatic reduction of disulfide bonds in lysosomes: Characterization of a gamma-interferon-inducible lysosomal thiol reductase (GILT). Proc. Natl. Acad. Sci. USA 2000, 97, 745-750. [CrossRef] [PubMed]

4. Lackman, R.L.; Jamieson, A.M.; Griffith, J.M.; Geuze, H.; Cresswell, P. Innate immune recognition triggers secretion of lysosomal enzymes by macrophages. Traffic 2007, 8, 1179-1189. [CrossRef] [PubMed]

5. Singh, R.; Cresswell, P. Defective cross-presentation of viral antigens in GILT-free mice. Science 2010, 328, 1394-1398. [CrossRef] [PubMed]

6. Rausch, M.P.; Hastings, K.T. Diverse cellular and organismal functions of the lysosomal thiol reductase GILT. Mol. Immunol. 2015, 68, 124-128. [CrossRef] [PubMed] 
7. Phan, G.Q.; Touloukian, C.E.; Yang, J.C.; Restifo, N.P.; Sherry, R.M.; Hwu, P.; Morton, K.E. Immunization of patients with metastatic melanoma using both class I-and class II-restricted peptides from melanoma-associated antigens. J. Immunother. 2003, 26, 349. [CrossRef]

8. Wang, P.; Zhou, D.; Kinraide, T.B.; Luo, X.; Li, L.; Li, D.; Zhang, H. Cell membrane surface potential $(\psi 0)$ plays a dominant role in the phytotoxicity of copper and arsenate. Plant Physiol. 2008, 148, 2134-2143. [CrossRef]

9. Chiang, H.S.; Maric, M. Lysosomal thiol reductase negatively regulates autophagy by altering glutathione synthesis and oxidation. Free. Radic. Biol. Med. 2011, 51, 688-699. [CrossRef]

10. Zhang, C.; Wu, L.; Luo, Y.; Zhang, H.; Christie, P. Identifying sources of soil inorganic pollutants on a regional scale using a multivariate statistical approach: Role of pollutant migration and soil physicochemical properties. Environ. Pollut. 2008, 151, 470-476. [CrossRef]

11. Conesa, J.A.; Gálvez, A.; Mateos, F.; Martín-Gullón, I.; Font, R. Organic and inorganic pollutants from cement kiln stack feeding alternative fuels. J. Hazard. Mater. 2008, 158, 585-592. [CrossRef] [PubMed]

12. Singh, H.P.; Batish, D.R.; Kaur, G.; Arora, K.; Kohli, R.K. Nitric oxide (as sodium nitroprusside) supplementation ameliorates Cd toxicity in hydroponically grown wheat roots. Environ. Exp. Bot. 2008, 63, 158-167. [CrossRef]

13. Fashola, M.; Ngole-Jeme, V.; Babalola, O. Heavy metal pollution from gold mines: Environmental effects and bacterial strategies for resistance. Int. J. Environ. Res. Public Health 2016, 13, 1047. [CrossRef] [PubMed]

14. Zhang, W.; Chen, W. Role of salicylic acid in alleviating photochemical damage and autophagic cell death induction of cadmium stress in Arabidopsis thaliana. Photochem. Photobiol. Sci. 2011, 10, 947-955. [CrossRef] [PubMed]

15. Wang, Y.; Loake, G.J.; Chu, C. Cross-talk of nitric oxide and reactive oxygen species in plant programed cell death. Front. Plant Sci. 2013, 4, 314. [CrossRef] [PubMed]

16. Takahashi, R.; Bashir, K.; Ishimaru, Y.; Nishizawa, N.K.; Nakanishi, H. The role of heavy-metal ATPases, HMAs, in zinc and cadmium transport in rice. Plant Signal. Behav. 2012, 7, 1605-1607. [CrossRef]

17. Gielen, H.; Remans, T.; Vangronsveld, J.; Cuypers, A. Toxicity responses of $\mathrm{Cu}$ and Cd: The involvement of miRNAs and the transcription factor SPL7. BMC Plant Biol. 2016, 16, 145. [CrossRef] [PubMed]

18. Li, J.; Wei, X.; Yu, P.; Deng, X.; Xu, W.; Ma, M.; Zhang, H. Expression of cadR enhances its specific activity for $\mathrm{Cd}$ detoxification and accumulation in Arabidopsis. Plant Cell Physiol. 2016, 57, 1720-1731. [CrossRef]

19. Rahoui, S.; Ben, C.; Chaoui, A.; Martinez, Y.; Yamchi, A.; Rickauer, M.; El Ferjani, E. Oxidative injury and antioxidant genes regulation in cadmium-exposed radicles of six contrasted Medicago truncatula genotypes. Environ. Sci. Pollut. Res. 2014, 21, 8070-8083. [CrossRef]

20. Abdel Latef, A.A.; Tran, L.S.P. Impacts of priming with silicon on the growth and tolerance of maize plants to alkaline stress. Front. Plant Sci. 2016, 7, 243. [CrossRef]

21. Kim, Y.H.; Khan, A.L.; Waqas, M.; Lee, I.J. Silicon regulates antioxidant activities of crop plants under abiotic-induced oxidative stress: A review. Front. Plant Sci. 2017, 8, 510. [CrossRef] [PubMed]

22. Lillig, C.H.; Holmgren, A. Thioredoxin and related molecules-from biology to health and disease. Antioxid. Redox Signal. 2007, 9, 25-47. [CrossRef] [PubMed]

23. Meyer, Y.; Vignols, F.; Reichheld, J.P. Classification of plant thioredoxins by sequence similarity and intron position. Methods Enzymol. 2002, 347, 394. [PubMed]

24. Collin, V.; Issakidis-Bourguet, E.; Marchand, C.; Hirasawa, M.; Lancelin, J.M.; Knaff, D.B.; Miginiac-Maslow, M. The Arabidopsis plastidial thioredoxins New functions and new insights into specificity. J. Biol. Chem. 2003, 278, 23747-23752. [CrossRef] [PubMed]

25. Laloi, C.; Rayapuram, N.; Chartier, Y.; Grienenberger, J.M.; Bonnard, G.; Meyer, Y. Identification and characterization of a mitochondrial thioredoxin system in plants. Proc. Natl. Acad. Sci. USA 2001, 98, 14144-14149. [CrossRef]

26. Serrato, A.J.; Cejudo, F.J. Type-h thioredoxins accumulate in the nucleus of developing wheat seed tissues suffering oxidative stress. Planta 2003, 217, 392-399. [CrossRef]

27. Balmer, Y.; Vensel, W.H.; Tanaka, C.K.; Hurkman, W.J.; Gelhaye, E.; Rouhier, N.; Buchanan, B.B. Thioredoxin links redox to the regulation of fundamental processes of plant mitochondria. Proc. Natl. Acad. Sci. USA 2004, 101, 2642-2647. [CrossRef]

28. Holmgren, A. Thioredoxin structure and mechanism: Conformational changes on oxidation of the active-site sulfhydryls to a disulfide. Structure 1995, 3, 239-243. [CrossRef]

29. Miki, H.; Funato, Y. Regulation of intracellular signalling through cysteine oxidation by reactive oxygen species. J. Biochem. 2012, 151, 255-261. [CrossRef] 
30. Cooper, C.E.; Patel, R.P.; Brookes, P.S.; Darley-Usmar, V.M. Nanotransducers in cellular redox signaling: Modification of thiols by reactive oxygen and nitrogen species. Trends Biochem. Sci. 2002, 27, 489-492. [CrossRef]

31. Nakamura, H.; Nakamura, K.; Yodoi, J. Redox regulation of cellular activation. Annu. Rev. Immunol. 1997, 15, 351-369. [CrossRef] [PubMed]

32. Sahaf, B.; Söderberg, A.; Spyrou, G.; Barral, A.M.; Pekkari, K.; Holmgren, A.; Rosén, A. Thioredoxin expression and localization in human cell lines: Detection of full-length and truncated species. Exp. Cell Res. 1997, 236, 181-192. [CrossRef] [PubMed]

33. Schenk, H.; Klein, M.; Erdbrügger, W.; Dröge, W.; Schulze-Osthoff, K. Distinct effects of thioredoxin and antioxidants on the activation of transcription factors NF-kappa B and AP-1. Proc. Natl. Acad. Sci. USA 1994, 91, 1672-1676. [CrossRef] [PubMed]

34. Hirota, K.; Murata, M.; Sachi, Y.; Nakamura, H.; Takeuchi, J.; Mori, K.; Yodoi, J. Distinct roles of thioredoxin in the cytoplasm and in the nucleus a two-step mechanism of redox regulation of transcription factor NF- $\mathrm{kB}$. J. Biol. Chem. 1999, 274, 27891-27897. [CrossRef]

35. Rollin-Genetet, F.; Berthomieu, C.; Davin, A.H.; Quéméneur, E. Escherichia coli thioredoxin inhibition by cadmium: Two mutually exclusive binding sites involving Cys32 and Asp26. Eur. J. Biochem. 2004, 271, 1299-1309. [CrossRef]

36. Lemaire, S.; Keryer, E.; Stein, M.; Schepens, I.; Issakidis-Bourguet, E.; Gérard-Hirne, C.; Jacquot, J.P. Heavy-Metal Regulation of Thioredoxin Gene Expression in Chlamydomonas reinhardtii. Plant Physiol. 1999, 120, 773-778. [CrossRef]

37. Ohkama-Ohtsu, N.; Kasajima, I.; Fujiwara, T.; Naito, S. Isolation and characterization of an Arabidopsis mutant that overaccumulates O-acetyl-L-Ser. Plant Physiol. 2004, 136, 3209-3222. [CrossRef]

38. Tuskan, G.A.; Difazio, S.; Jansson, S.; Bohlmann, J.; Grigoriev, I.; Hellsten, U.; Schein, J. The genome of black cottonwood, Populus trichocarpa (Torr. Gray). Science 2006, 313, 1596-1604. [CrossRef]

39. Clough, S.J.; Bent, A.F. Floral dip: A simplified method for Agrobacterium-mediated transformation of Arabidopsis thaliana. Plant J. 1998, 16, 735-743. [CrossRef]

40. Zang, D.; Wang, C.; Ji, X.; Wang, Y. Tamarix hispida zinc finger protein ThZFP1 participates in salt and osmotic stress tolerance by increasing proline content and SOD and POD activities. Plant Sci. 2015, 235, 111-121. [CrossRef]

41. Maric, M.; Arunachalam, B.; Phan, U.T.; Dong, C.; Garrett, W.S.; Cannon, K.S.; Cresswell, P. Defective antigen processing in GILT-free mice. Science 2001, 294, 1361-1365. [CrossRef] [PubMed]

42. Yang, L.; Cao, X.; Ji, X.; Liu, H.; Wu, H.; Gu, W.; Zhang, S. Molecular structure, tissue distribution and functional characterization of interferon- $\gamma$-inducible lysosomal thiol reductase (GILT) gene in chicken (Gallus gallus). Vet. Immunol. Immunopathol. 2013, 153, 140-145. [CrossRef] [PubMed]

43. Woods, I.G.; Wilson, C.; Friedlander, B.; Chang, P.; Reyes, D.K.; Nix, R.; Talbot, W.S. The zebrafish gene map defines ancestral vertebrate chromosomes. Genome Res. 2005, 15, 1307-1314. [CrossRef] [PubMed]

44. Liu, N.; Zhang, S.; Liu, Z.; Gaowa, S.; Wang, Y. Characterization and expression of gamma-interferon-inducible lysosomal thiol reductase (GILT) gene in amphioxus Branchiostoma belcheri with implications for GILT in innate immune response. Mol. Immunol. 2007, 44, 2631-2637. [CrossRef]

45. Dan, W.B.; Wang, S.L.; Liang, J.Q.; Zhang, S.Q. Molecular cloning and expression analysis of porcine $\gamma$-interferon-inducible lysosomal thiol reductase (GILT). Vet. Immunol. Immunopathol. 2008, 126, 163-167. [CrossRef]

46. Zheng, W.; Chen, X. Cloning and expression analysis of interferon- $\gamma$-inducible-lysosomal thiol reductase gene in large yellow croaker (Pseudosciaena crocea). Mol. Immunol. 2006, 43, 2135-2141. [CrossRef]

47. Kongton, K.; McCall, K.; Phongdara, A. Identification of gamma-interferon-inducible lysosomal thiol reductase (GILT) homologues in the fruit fly Drosophila melanogaster. Dev. Comp. Immunol. 2014, 44, 389-396. [CrossRef]

48. Phan, U.T.; Maric, M.; Dick, T.P.; Cresswell, P. Multiple species express thiol oxidoreductases related to GILT. Immunogenetics 2001, 53, 342-346. [CrossRef]

49. Lackman, R.L.; Cresswell, P. Exposure of the promonocytic cell line THP-1 to Escherichia coli induces IFN- $\gamma$-inducible lysosomal thiol reductase expression by inflammatory cytokines. J. Immunol. 2006, 177, 4833-4840. [CrossRef] 
50. Li, P.; Haque, M.A.; Blum, J.S. Role of disulfide bonds in regulating antigen processing and epitope selection. J. Immunol. 2002, 169, 2444-2450. [CrossRef]

51. Hastings, K.T.; Cresswell, P. Disulfide reduction in the endocytic pathway: Immunological functions of gamma-interferon-inducible lysosomal thiol reductase. Antioxid. Redox Signal. 2011, 15, 657-668. [CrossRef] [PubMed]

52. McInnis, S.M.; Desikan, R.; Hancock, J.T.; Hiscock, S.J. Production of reactive oxygen species and reactive nitrogen species by angiosperm stigmas and pollen: Potential signalling crosstalk? New Phytol. 2006, 172, 221-228. [CrossRef] [PubMed]

53. Wang, R.F. Enhancing antitumor immune responses: Intracellular peptide delivery and identification of MHC class II-restricted tumor antigens. Immunol. Rev. 2002, 188, 65-80. [CrossRef] [PubMed]

54. Navrot, N.; Rouhier, N.; Gelhaye, E.; Jacquot, J.P. Reactive oxygen species generation and antioxidant systems in plant mitochondria. Physiol. Plant. 2007, 129, 185-195. [CrossRef]

55. Pitzschke, A.; Forzani, C.; Hirt, H. Reactive oxygen species signaling in plants. Antioxid. Redox Signal. 2006, 8, 1757-1764. [CrossRef]

56. Jacquot, J.P.; Lancelin, J.M.; Meyer, Y. Thioredoxins: Structure and function in plant cells. New Phytol. 1997, 136, 543-570. [CrossRef]

57. Schürmann, P.; Jacquot, J.P. Plant thioredoxin systems revisited. Annu. Rev. Plant. Biol. 2000, 51, 371-400. [CrossRef]

58. Hossain, Z.; Komatsu, S. Contribution of proteomic studies towards understanding plant heavy metal stress response. Front. Plant. Sci. 2013, 3, 310. [CrossRef]

59. Dos Santos, C.V.; Rey, P. Plant thioredoxins are key actors in the oxidative stress response. Trends Plant. Sci. 2006, 11, 329-334. [CrossRef]

60. Zhou, R.; Tardivel, A.; Thorens, B.; Choi, I.; Tschopp, J. Thioredoxin-interacting protein links oxidative stress to inflammasome activation. Nat. Immunol. 2010, 11, 136. [CrossRef]

61. You, J.; Chan, Z. ROS regulation during abiotic stress responses in crop plants. Front. Plant. Sci. 2015, 6, 1092. [CrossRef] [PubMed]

62. Salt, D.E.; Wagner, G.J. Cadmium transport across tonoplast of vesicles from oat roots. Evidence for a Cd2+/H+ antiport activity. J. Biol. Chem. 1993, 268, 12297-12302. [PubMed]

(C) 2019 by the authors. Licensee MDPI, Basel, Switzerland. This article is an open access article distributed under the terms and conditions of the Creative Commons Attribution (CC BY) license (http://creativecommons.org/licenses/by/4.0/). 